\title{
Association of the tumour necrosis factor $\alpha-308$ but not the interleukin $10-627$ promoter polymorphism with genetic susceptibility to primary sclerosing cholangitis
}

S A Mitchell, J Grove, A Spurkland, K M Boberg, K A Fleming, C P Day, E Schrumpf, R W Chapman, the European Study Group of Primary Sclerosing Cholangitis

\begin{abstract}
Background and aims-Primary sclerosing cholangitis (PSC) is a chronic cholestatic liver disease of unknown aetiology. Abnormalities in immune regulation and genetic associations suggest that PSC is an immune mediated disease. Several polymorphisms within the tumour necrosis factor $\alpha(\mathrm{TNF}-\alpha)$ and interleukin 10 (IL10) promoter genes have been described which influence expression of these cytokines. This study examines the possible association between polymorphisms at the -308 and -627 positions in the TNF- $\alpha$ and IL-10 promoter genes, respectively, and susceptibility to PSC.

Methods-TNF-a -308 genotypes were studied by polymerase chain reaction (PCR) in 160 PSC patients from Norway and the UK compared with 145 ethnically matched controls. IL-10 -627 genotypes were studied by PCR in 90 PSC patients compared with 84 ethnically matched controls.
\end{abstract}

Results-A total of $16 \%$ of Norwegian PSC patients and $12 \%$ of British PSC patients were homozygous for the TNF2 allele compared with $3 \%$ and $6 \%$ of respective controls. The TNF2 allele was present in $60 \%$ of PSC patients versus $30 \%$ of controls $\left(O R_{\text {combined data }}=3.2(95 \%\right.$ confidence intervals (CI) $1.8-4.5) ; p_{\text {corr }}=10^{-5}$ ). The association between the TNF2 allele and susceptibility to PSC was independent of the presence of concurrent inflammatory bowel disease (IBD) in the PSC patients; $61 \%$ of PSC patients without IBD had TNF2 compared with $30 \%$ of controls $\left(O R_{\text {combined data }}=3.2(95 \%\right.$ CI 1.2-9.0); $\mathbf{p}_{\text {corr }}=0.006$ ). There was no difference in the -627 IL-10 polymorphism distributions between patients and controls in either population. The increase in TNF2 allele in PSC patients only occurs in the presence of DRB1*0301 (DR3) and B8. In the combined population data, DRB1*0301 showed a stronger association with susceptibility to PSC than both the TNF2 and B8 alleles $\left(\mathrm{OR}_{\text {combined data }}=3.8, \mathrm{p}_{\text {corr }}=10^{-6} v\right.$ $\mathbf{O R}_{\text {combined data }}=3.2, \mathbf{p}_{\text {corr }}=10^{-5} v \mathbf{O R}_{\text {combined data }}$ $=3.41, p_{\text {corr }}=10^{-4}$, respectively).

Conclusions-This study identified a significant association between possession of the TNF2 allele, a $\mathbf{G} \rightarrow \mathbf{A}$ substitution at position -308 in the TNF- $\alpha$ promoter, and susceptibility to PSC. This association was secondary to the association of PSC with the A1-B8-DRB1*0301-DQA1`0501DQB $1{ }^{\star} 0201$ haplotype. No association was found between the IL-10 -627 promoter polymorphism and PSC.

(Gut 2001;49:288-294)

Keywords: primary sclerosing cholangitis; tumour necrosis factor; interleukin 10; genetic polymorphism

Primary sclerosing cholangitis (PSC) is a chronic cholestatic liver disease characterised by a progressive obliterating inflammatory fibrosis of the intrahepatic and extrahepatic bile ducts. ${ }^{1}$ Loss of functioning bile ducts leads to biliary cirrhosis and eventually hepatic failure. Its aetiology is unknown but the observation of abnormal immune regulation and genetic associations with certain HLA genes supports the hypothesis that PSC is an immune mediated disease. A number of studies have previously been performed with the aim of identifying candidate PSC susceptibility loci, especially within the human major histocompatibility complex on chromosome 6. These studies have identified two susceptibility haplotypes, A1-B8DRB $1{ }^{\star} 0301-\mathrm{DQA} 1{ }^{\star} 0501-\mathrm{DQB} 1{ }^{\star} 0201$ and DRB1*1301-DQA $1{ }^{\star} 0103-\mathrm{DQB} 1{ }^{\star} 0603 .^{2-5}$ These two haplotypes account for about $80 \%$ of PSC patients. ${ }^{5}$ However, other candidate PSC susceptibility loci may be involved.

The genes for tumour necrosis factor $\alpha$ (TNF- $\alpha$ ) and interleukin 10 (IL-10) in particular have attracted considerable attention as possible contributors to susceptibility or resistance to infectious, immune mediated, and autoimmune diseases. The TNF- $\alpha$ gene is located in the class III HLA region between the HLA-B and DRB3 loci. ${ }^{6}$ A number of polymorphisms have been described within the TNF- $\alpha$ promoter region but the biallelic polymorphism at position -308 is of particular interest as an increased frequency of the rare allele TNF $-308 \mathrm{~A}$ (termed TNF2 as opposed to the common allele TNF-308G or TNF1) has been reported in autoimmune disorders such as rheumatoid arthritis, systemic lupus erythematous, and coeliac disease..$^{7-9}$ The functional significance of this biallelic polymorphism remains controversial; the majority of studies ${ }^{10-12}$ using reporter gene constructs have suggested

Abbreviations used in this paper: PSC, primary sclerosing cholangitis; IL-10, interleukin 10 ; TNF- $\alpha$, tumour necrosis factor $\alpha$;BD, inflammatory bowel disease; PCR, polymerase chain reaction; OR, odds ratio; PBC, primary biliary cirrhosis. 
that the TNF2 allele compared with the TNF1 allele is a more powerful transcriptional activator, although this finding is not universal. ${ }^{13}$ TNF2 is part of the extended HLA-A1-B8DR3-DQ2 haplotype ${ }^{14}$ and individuals with this haplotype may produce high levels of TNF- $\alpha$ and be more susceptible to a spectrum of autoimmune diseases. ${ }^{8}$

IL-10 is an important immunoregulatory cytokine which suppresses CD4+ T helper clones (which secrete IL-2, interferon $\gamma$, and TNF- $\alpha$ ), Th1 clones, and promotes the immunomodulatory $\mathrm{T}$ helper, $\mathrm{Th} 2$, clones (which secrete IL-4, IL-10, and IL-13). ${ }^{15}$ Reciprocal regulation mediated by secretion of cytokines may be an important determinant of the balance between Th1 and Th2 cells and critical for immunoregulation. If $\mathrm{T}$ cells have a reduced capacity to produce IL-10 in response to a stimulus, Th1 responses may continue unabated with the breakdown of peripheral tolerance and the potential for autoimmunity to develop.

Disease association studies and studies correlating IL-10 genotype with IL-10 secretion by peripheral blood mononuclear cells provide evidence for an effect of the -627 polymorphism on IL-10 expression. The $-627^{\star} \mathrm{A}$ allele is associated with severe asthma ${ }^{16}$ and low IL-10 tissue concentrations ${ }^{17}$ while the $-627^{\star} \mathrm{C}$ allele, found in high IL-10 secretors, ${ }^{18}$ is associated with renal disease in systemic lupus erythematosus. ${ }^{19} \mathrm{We}$ have previously observed decreased expression of IL-10 mRNA in the livers of patients with PSC suggesting that decreased secretion of this cytokine may be implicated in the pathogenesis of PSC. ${ }^{20}$ Given the antifibrogenic and immunoregulatory effects of IL-10, we hypothesised that polymorphism at position -627 in the IL-10 promoter may be functional in terms of control of cytokine secretion in vivo ${ }^{21}$ resulting in low IL-10 production, and so could represent a potential susceptibility locus in PSC.

In this study we sought to examine the role of polymorphisms in both the TNF- $\alpha$ and IL-10 promoters (at positions -308 and -627 , respectively) in determining susceptibility to and disease progression within PSC, by comparing their frequencies in two distinct but well defined Northern European PSC populations with geographically matched controls.

\section{Patients and methods}

SUBJECTS

One hundred and ten unrelated Norwegian PSC patients attending the National Hospital, Oslo, Norway, and 50 British PSC patients attending the liver clinic at the Oxford Radcliffe

Table 1 Patient characteristics (number (\%))

\begin{tabular}{|c|c|c|c|c|c|}
\hline \multirow[b]{2}{*}{$\mathrm{n}$} & $\begin{array}{l}\text { Norwegian } \\
\text { PSC patients }\end{array}$ & \multirow{2}{*}{$\begin{array}{l}\begin{array}{l}\text { Norwegian } \\
\text { controls }\end{array} \\
110\end{array}$} & \multicolumn{2}{|c|}{$\begin{array}{l}\text { British PSC } \\
\text { patients }\end{array}$} & \multirow{2}{*}{$\begin{array}{l}\begin{array}{l}\text { British } \\
\text { controls }\end{array} \\
35\end{array}$} \\
\hline & 110 & & 50 & & \\
\hline Male & $81 \quad(73)$ & $77(70)$ & 33 & (66) & $24(69)$ \\
\hline Mean age at presentation (y) & $28.7(10-73)$ & & 47.7 & $(17-78)$ & \\
\hline Mean follow up period (months) & 141 & & 67 & & \\
\hline Dead & (18) & & 4 & (8) & \\
\hline Cholangiocarcinoma & (12) & & 2 & (4) & \\
\hline Liver transplanted & (17) & & 2 & (4) & \\
\hline Concurrent IBD & $(85)$ & & 43 & $(86)$ & \\
\hline No concurrent IBD & (15) & & 7 & (14) & \\
\hline
\end{tabular}

PSC, primary sclerosing cholangitis; IBD, inflammatory bowel disease.
Hospital, Oxford, UK were included in the study. The diagnosis of PSC was based on accepted clinical, biochemical, radiological, and histological criteria in the absence of evidence of secondary cholangitis, hepatobiliary malignancy, viral, metabolic, or other autoimmune liver disease. In all cases informed consent was obtained before inclusion in the study. Details of the patients are given in table 1 . Mean age at presentation was 28.7 years and 47.7 years in the Norwegian and British patients, respectively. Over two thirds of each population was male and the majority $(\sim 85 \%)$ had concurrent inflammatory bowel disease (IBD). IBD was diagnosed using the characteristic endoscopic and histological criteria. In the $15 \%$ of PSC patients without IBD included in this study, a diagnosis of IBD was excluded by endoscopic biopsy in all but one of the British patients and in the majority of Norwegian patients.

The observation period was calculated as the interval from the first symptom, sign, or investigation consistent with a diagnosis of PSC until the end points of death or liver transplantation or the most recent attendance in the liver clinic.

A total of 110 Norwegian blood donors and 35 British citizens, geographically and ethnically matched, were used as the control population. None of the control subjects had symptoms, signs, or biochemical evidence of liver disease at recruitment.

\section{DNA EXTRACTION}

Genomic DNA was extracted from EDTA preserved whole blood using standard techniques.

\section{GENOTYPING}

Genotyping for the cytokine gene polymorphisms was performed by polymerase chain reaction (PCR) amplification using sequence specific primers and/or subsequent restriction fragment length polymorphism. All Norwegian and British patients and controls were included in TNF- $\alpha-308$ genotyping. Sufficient DNA for IL-10 -627 genotyping was only available for 59 Norwegian patients, 53 Norwegian controls, 31 British patients, and 31 British controls. Each batch of PCR reactions included a control reaction to which no DNA had been added to ensure that no contamination of samples had occurred, and two samples of known genotype. The product of each amplification or digestion was then electrophoresed on a $2 \%$ agarose gel containing ethidium bromide and visualised under ultraviolet light.

TNF- $\alpha-308$ GENOTYPING

Polymorphism at position -308 in the TNF- $\alpha$ promoter was determined by PCR amplification using sequence specific primers, as described by Verjans and colleagues. ${ }^{22}$ Four primers were used: the 3 ' primer $\mathrm{C} 1$ (position $-144 /-164$ : 5'-TCTCGGTTTCTTCTGGA T CG-3') was used in combination with either the $5^{\prime}$ primer C2 (position -328/-308G: 5'ATAGGTTTTGAGGCATGG-3'), complementary to the TNF1 allele, or the 5' primer C3 (-328/-308A: 5'-ATAGGTTTTGAGGGGC ATGA-3') which is complementary to the 
TNF2 allele. For each DNA sample, two parallel reactions were performed. The primer pair $\mathrm{C} 1 / \mathrm{C} 2$ were used to produce specific amplification of TNF1; C1/C3 were used to amplify the TNF2 allele. As an internal control, primer D (position -675 to -655 : 5'-GAGTGTCCGG GTCAGAATGA-3') was added to each reaction. Amplification was carried out using the cycling conditions previously described. ${ }^{23}$

IL-10 - 627 GENOTYPING

The IL-10 -627 polymorphism was detected by PCR-restriction fragment length polymorphism using the primers: 5'-GGT AGG TGA GAG TGA GGT GG-3' and 5'-GGT GAG GAG TAG GTG AGT AGG-3' which amplify a $412 \mathrm{bp}$ fragment containing the -627 polymorphism. ${ }^{24}$ DNA samples were amplified in $50 \mu \mathrm{l}$ of $\mathrm{KCl}$ reaction buffer (Bioline, London, UK) containing $200 \mu \mathrm{M}$ dNTP, $0.25 \mu \mathrm{M}$ of each primer, $1 \mu \mathrm{g}$ of DNA sample, and $2 \mathrm{U}$ of Taq polymerase (Bioline) for 35 cycles at $94^{\circ} \mathrm{C}$ for one minute, $50^{\circ} \mathrm{C}$ for one minute, and $70^{\circ} \mathrm{C}$ for one minute, followed by one cycle at $70^{\circ} \mathrm{C}$ for 10 minutes. The PCR product $(10 \mu \mathrm{l})$ from each reaction was then incubated for three hours at $37^{\circ} \mathrm{C}$ with 3 units of Rsa I (which cleaves DNA fragments possessing the rarer A allele but not the more common $G$ allele at position -627).

HLA-DR TYPING

All patients and controls were previously typed for HLA DRB1, DQA1, and DQB1 using different genomic typing methods based on in vitro amplification of DNA and SSO probing, as previously described. ${ }^{5}$ Most PSC patients and all controls were serologically typed for HLA-B8.

STATISTICAL ANALYSIS

The frequencies of alleles in patients and controls were compared using the $\chi^{2}$ and Fisher's exact probability tests, as appropriate, with the Epistat statistical software (EPI Info version 6.0; CDC, Atlanta, Georgia, USA). The level of significance was set at 0.05 . Bonferoni's correction for multiple testing was applied as follows: for comparisons of TNF- $\alpha$ and IL-10 genotypes, a correction factor of 8 was used (the number of genotypes plus the two HLA alleles DRB $1{ }^{\star} 0301$ and $\mathrm{B} 8$ ) and a correction factor of 3 for stratification analysis (number of tests performed in the analysis). Data from the Norwegian and British populations were combined using a method for analysing combined odds ratios and $\chi^{2}$ originally described by Wolf and modified by Haldane. ${ }^{25}$ Haldanes's analysis of combined data includes both an estimation for combined relative risk/odds ratio (OR) and an estimation of the heterogeneity of the combined data. Stratification analysis was performed to determine the strongest association between haplotypes and susceptibility to PSC using a modification of the methods described by Svejgaard and Ryder. ${ }^{26}$

Table 2 Distribution of the -308 tumour necrosis factor a (TNF-a) genotypes in all PSC patients and PSC patients with or without IBD versus local controls

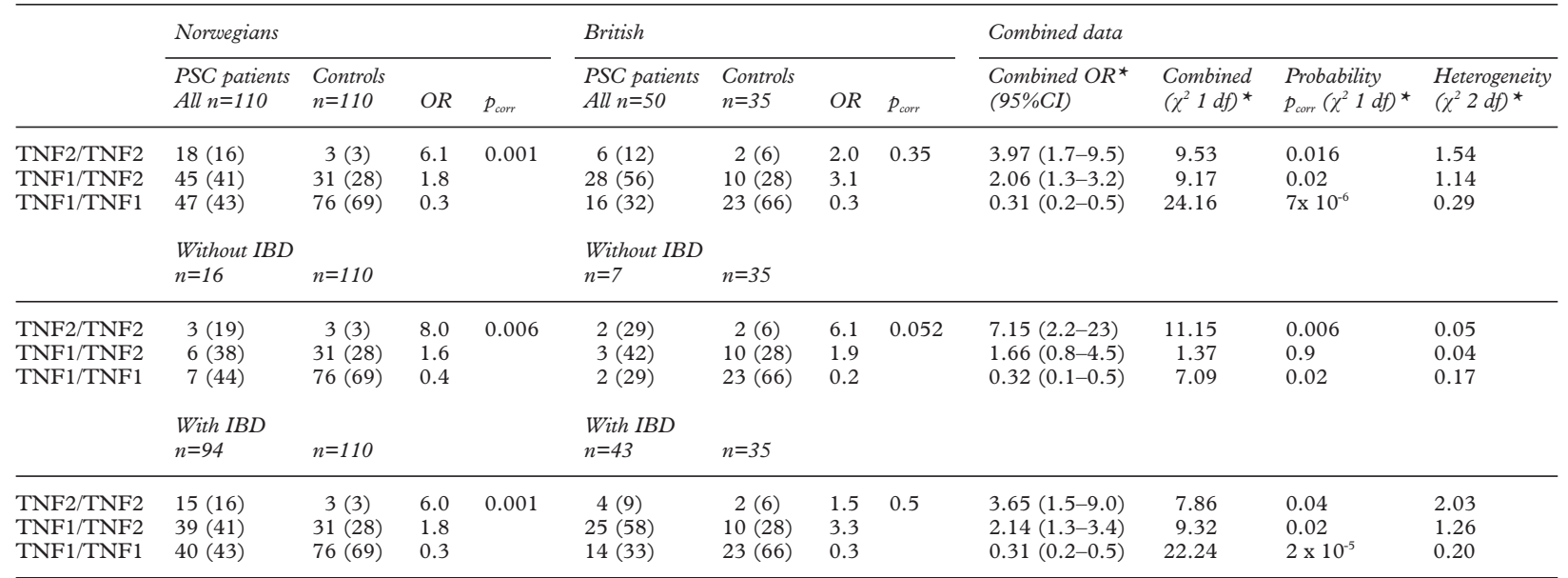

Values for patients and controls are number (\%) of individuals with the given genotype.

$\mathrm{p}_{\text {corr }}$, corrrected probability comparing the genotype distribution for PSC patients and controls

${ }^{\star}$ Method for estimating combined OR and $\chi^{2}$ according to Wolf, modified by Haldane, as given in Tiwaris and Terasaki. ${ }^{25}$

PSC, primary sclerosing cholangitis; IBD, inflammatory bowel disease.

Table 3 Distribution of the-627 IL-10 genotypes in all PSC patients versus local controls

\begin{tabular}{|c|c|c|c|c|c|c|c|c|c|c|c|c|}
\hline & \multicolumn{4}{|l|}{ Norwegians } & \multicolumn{4}{|l|}{ British } & \multicolumn{4}{|l|}{ Combined data } \\
\hline & $\begin{array}{l}\text { PSC patients } \\
(n=59)\end{array}$ & $\begin{array}{l}\text { Controls } \\
(n=53)\end{array}$ & $O R$ & $p$ & $\begin{array}{l}\text { PSC patients } \\
(n=31)\end{array}$ & $\begin{array}{l}\text { Controls } \\
(n=31)\end{array}$ & $O R$ & $p$ & Combined $O R^{\star}$ & $\begin{array}{l}\text { Combined } \\
\left(\chi^{2} 11 d f\right)^{\star}\end{array}$ & $\begin{array}{l}\text { Probability } \\
\left(\chi^{2} 1 d f\right)^{\star}\end{array}$ & $\begin{array}{l}\text { Heterogeneity } \\
\left(\chi^{2} 2 d f\right)^{\star}\end{array}$ \\
\hline \multicolumn{13}{|c|}{ IL-10 -627 } \\
\hline $\mathrm{A} / \mathrm{A}$ & $3(5)$ & $2(3)$ & 1.3 & 0.8 & $1(3)$ & $1(3)$ & 1.0 & 1.0 & $1.17(0.3-3.9)$ & 0.06 & 0.8 & 0.04 \\
\hline $\mathrm{C} / \mathrm{A}$ & $27(46)$ & $20(37)$ & 1.4 & 0.4 & $11(35)$ & $12(39)$ & 0.9 & 0.8 & $1.18(0.6-2.1)$ & 0.29 & 0.6 & 0.51 \\
\hline $\mathrm{C} / \mathrm{C}$ & 29 (49) & $31(58)$ & 0.7 & 0.3 & $19(62)$ & $18(58)$ & 1.1 & 0.8 & $0.82(0.5-1.5)$ & 0.42 & 0.5 & 0.62 \\
\hline
\end{tabular}

Values for patients and controls are number (\%) of individuals with the given genotype.

${ }^{\star}$ Method for estimating combined OR and $\chi^{2}$ according to Wolf, modified by Haldane, as given in Tiwaris and Terasaki. ${ }^{25}$

IL-10, interleukin 10; PSC, primary sclerosing cholangitis. 


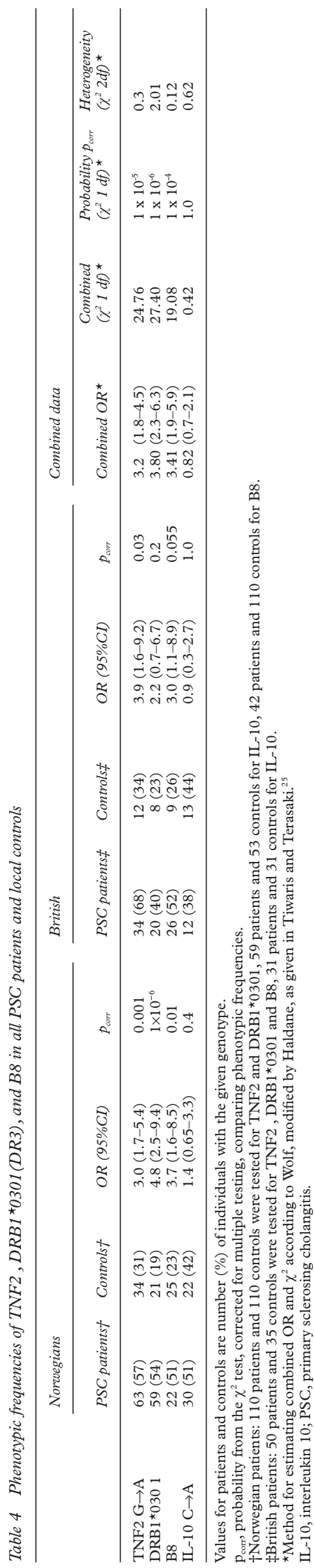

\section{Results}

-308 TNF1/TNF2 POLYMORPHISM

The frequency distribution of -308 TNF- $\alpha$ polymorphism genotypes among healthy local controls and Norwegian and British PSC patients is shown in table 2 . The phenotypic frequency of the TNF2 allele compared with the IL-10 $-627^{\star} \mathrm{A}$ allele and HLA alleles in PSC patients and controls is given in table 4 . Tables 5 and 6 show the stratification analysis of TNF2 in comparison with HLADRB1 ${ }^{\star} 0301$ and HLA-B8, respectively. In the British population, the difference in the distribution of the TNF- $\alpha-308$ genotypes failed to reach significance after correcting for multiple testing. In the Norwegian population there was a significant difference in the distribution of the TNF- $\alpha-308$ genotypes in patients versus controls (OR 6.1 (95\% confidence interval (CI) 2.1-18.7); $\mathrm{p}=0.001)$. This difference was due to an excess of the TNF2 allele which was present in $57 \%$ of the Norwegian PSC patients versus $31 \%$ of their controls (OR 3.0 (95\% CI $1.7-5.4) ; \mathrm{p}=0.001)$. Eighteen of $110(16 \%)$ Norwegian PSC patients were TNF2/TNF2 homozygotes compared with only $3 / 110(3 \%)$ Norwegian controls.

In the combined data of both populations, the TNF2 allele was present in $60 \%$ of PSC patients versus $33 \%$ of controls $\left(\mathrm{OR}_{\text {combined }}\right.$ data $=3.2(95 \%$ CI $\left.1.8-4.5) ; p_{\text {corr }}=10^{-5}\right)$. The DRB $1{ }^{\star} 0301$ allele was present in $49 \%$ of PSC patients versus $20 \%$ of controls $\left(\mathrm{OR}_{\text {combined }}\right.$ data $=3.8\left(95 \%\right.$ CI 2.3-6.3); $\left.\mathrm{p}_{\text {corr }}=10^{-6}\right)$ and the B8 allele in $52 \%$ of PSC patients tested versus $21 \%$ of controls $\left(\mathrm{OR}_{\text {combined data }}=3.41(95 \% \mathrm{CI}\right.$ $1.9-5.9) ; \mathrm{p}_{\text {corr }}=10^{-4}$ ). The DRB $1^{\star} 0301$ allele showed a stronger association with susceptibility to PSC than either TNF2 or B8.

The association between the TNF2 allele and susceptibility to PSC was independent of the presence of concurrent IBD. Separate analysis of PSC patients with and without underlying IBD is included in table $2 ; 61 \%$ (14/23) of PSC patients without IBD had the TNF2 allele compared with $30 \%$ of controls $\left(\mathrm{OR}_{\text {combined }}\right.$ data $=3.2 \quad(95 \% \quad$ CI $\quad 1.2-9.0)$; $\mathrm{p}_{\text {corr }}=0.006$ ), a similar proportion to the whole PSC population. Three of 16 Norwegian and 2/7 British PSC patients without underlying IBD were TNF2/TNF2 homozygotes. In the combined data of populations, the association between TNF2 allele and susceptibility to PSC appeared to be stronger in PSC patients without IBD $(n=23)$ than in those with IBD $(n=137)$ but this probably reflects the small numbers in the former group.

TNF- $\alpha$ allele frequency was similar in males and females and there was no difference in age between patients with different genotypes. The TNF- $\alpha$ genotype did not significantly correlate with disease progression, as defined by the observation time from diagnosis to significant clinical outcome (liver transplantation, development of cholangiocarcinoma, death).

$-627 \mathrm{C} \rightarrow$ A INTERLEUKIN 10 POLYMORPHISM

The genotypic distribution of the -627 IL-10 polymorphism is given in table 3 . There was no significant difference in the -627 IL-10 
Table 5 Stratification analysis of TNF2 in comparison with HLA -DRB1 *0301

\begin{tabular}{|c|c|c|c|c|c|}
\hline \multicolumn{2}{|l|}{ Phenotype } & \multirow[b]{2}{*}{ PSC patients† } & \multirow[b]{2}{*}{ Controlst } & \multicolumn{2}{|c|}{ Comparison with DR3-/TNF2- } \\
\hline$D R B 11^{\star} 0301$ & $T N F 2$ & & & OR $(95 \% C I)$ & Probability $p_{\text {corr }}$ \\
\hline+ & + & 70 & 25 & $4.8(2.6-8.8)$ & $2 \times 10^{-6}$ \\
\hline+ & - & 9 & 4 & $3.8(1.0-14.6)$ & 0.16 \\
\hline - & + & 27 & 23 & $2.0(1.0-4.0)$ & 0.2 \\
\hline - & - & 54 & 93 & & \\
\hline
\end{tabular}

$\mathrm{t}_{\mathrm{n}}=160$ PSC patients and 145 controls.

PSC, primary sclerosing cholangitis.

Table 6 Stratification analysis of TNF2 in comparison with HLA-B8

\begin{tabular}{|c|c|c|c|c|c|}
\hline \multicolumn{2}{|c|}{ Phenotype } & \multirow[b]{2}{*}{ PSC patients } & \multirow[b]{2}{*}{ Controls } & \multicolumn{2}{|c|}{ Comparison with B8-/TNF2- } \\
\hline$B 8$ & $T N F 2$ & & & OR $(95 \% C I)$ & Probability $p_{\text {corr }}$ \\
\hline+ & + & 42 & 30 & $4.3(2.2-8.3)$ & $2 \times 10^{-6}$ \\
\hline+ & - & 6 & 4 & $4.5(1.0-15.6)$ & 0.06 \\
\hline- & + & 14 & 17 & $2.5(1.0-6.1)$ & 0.12 \\
\hline - & - & 31 & 94 & & \\
\hline
\end{tabular}

$\mathrm{N}=93$ PSC patients and 145 controls.

PSC, primary sclerosing cholangitis.

polymorphism distributions between patients and controls in either the Norwegian or British populations. $\mathrm{C} \rightarrow \mathrm{A}$ substitution at position -627 did not appear to be associated with disease progression or severity.

DRB $1{ }^{\star} 0301$ AND STRATIFICATION ANALYSIS

Susceptibility to PSC is associated with two haplotypes, A1-B8-DRB $1{ }^{\star} 0301-D Q A 1{ }^{\star} 0501-$ DQB $1^{\star} 0201$ and DRB $1{ }^{\star} 1301-\mathrm{DQA}{ }^{\star}{ }^{\star} 0103-$ DQB $1{ }^{\star} 0603 .^{5}{ }^{27}$ As TNF2 is known to be in strong linkage disequilibrium with the A1-B8DRB $1{ }^{\star} 0301-\mathrm{DQA} 1{ }^{\star} 0501-\mathrm{DQB} 1{ }^{\star} 0201$ haplotype, over representation of TNF2 in PSC populations may be secondary to a primary association of PSC with other genes carried by this haplotype. Table 5 illustrates stratification analysis to determine if the association between PSC and TNF2 is a consequence of linkage with $\mathrm{DRB} 1{ }^{\star} 0301$ or independent of this allele. TNF2 was significantly increased in PSC patients only in the presence of $\mathrm{DRB} 1^{\star} 0301$. This suggests that any association between susceptibility to PSC and TNF2 may be the result of linkage with $\mathrm{DRB} 1^{\star} 0301$. Similarly, table 6 illustrates that TNF2 is significantly increased in PSC patients only in the presence of HLA-B8.

\section{Discussion}

In the present study we have identified a significant association between possession of the TNF2 allele, a $\mathrm{G} \rightarrow \mathrm{A}$ substitution at position -308 in the TNF- $\alpha$ promoter, and susceptibility to PSC. This association was secondary to the association of PSC with the $\mathrm{DRB} 1{ }^{\star} 0301$ allele. We found no association between the IL-10 -627 polymorphism and PSC in either the Norwegian or British populations.

The TNF2 allele has been shown not only to be in strong linkage disequilibrium with the "autoimmune" haplotype HLA-A1-B8DRB1*0301-DQA1 ${ }^{\star} 0501-\mathrm{DQB} 1{ }^{\star} 0201$ but also may be implicated in the regulation of TNF- $\alpha$ transcription. ${ }^{14}$ Wilson and colleagues, ${ }^{12}$ using reporter gene constructs, have shown sevenfold higher levels of transcription from TNF2 compared with TNF1 in unstimulated and PMA stimulated Raji cells. Kroeger and colleagues $^{10}$ have reported a twofold greater level of transcription with the TNF2 compared with the TNF1 allele in a transfection assay involving luciferase as the reporter gene. However, data relating $\mathrm{TNF}-\alpha$ genotype to TNF- $\alpha$ production from peripheral mononuclear cells of heart transplant recipients has not confirmed the functional significance of the biallelic polymorphism at position -308 in the TNF- $\alpha$ promoter. ${ }^{28}$ TNF- $\alpha$ is believed to have an important role in the pathogenesis of severe infectious disease, and fatal cerebral malaria is associated with high circulating levels of this cytokine. The TNF2 allele is independently associated with increased susceptibility to cerebral malaria in Gambian children. ${ }^{29}$ Studies in autoimmune diseases have been less convincing although there is evidence in several autoimmune connective tissue disorders of a genetic contribution from the TNF locus. ${ }^{679}$

A number of studies have addressed the role of the TNF- $\alpha$ polymorphism in autoimmune liver diseases such as primary biliary cirrhosis (PBC). Gordon and colleagues ${ }^{30}$ found that PBC was significantly correlated with noncarriage of the TNF2 allele, implying that this allele confers protection against disease susceptibility in PBC. Jones and colleagues ${ }^{31}$ found no evidence for involvement of TNF- $\alpha$ promoter polymorphisms in the genetic predisposition to PBC but increased TNF1 homozygotes in patients with advanced disease suggested that this allele may be linked to disease progression. Bernal and colleagues ${ }^{32}$ were the first to report an association between the TNF2 allele and susceptibility to PSC. The authors were unable to determine whether the association was primary and independent or a result of linkage with the extended haplotype A1-B8DRB $1{ }^{\star} 0301-\mathrm{DQA} 1{ }^{\star} 0501-\mathrm{DQB}{ }^{\star}{ }^{\star} 0201$.

Similarly, in the present study we were unable to show that the association between the TNF2 allele and susceptibility to PSC was independent of this haplotype. In particular, we could not distinguish the association between susceptibility to PSC with TNF2 from that with HLA-DRB $1{ }^{\star} 0301$ (DR3) or HLA-B8 in either Norwegian or British PSC patients. In Norwegian PSC patients, DRB $1^{\star} 0301$ appeared to be more strongly associated with PSC than TNF2 whereas in British PSC patients the association with $\mathrm{DRB} 1{ }^{\star} 0301$ was weaker and that with TNF2 and the HLA class I allele, B8, marginally stronger (table 4 ). The significance of these variations between study populations is unclear. The TNF2 allele was marginally increased in $\mathrm{DRB} 1{ }^{\star} 0301$ negative (OR 2.0 (95\% CI 1.0-4.0); p=0.2) and B8 negative (OR 2.5 (95\% CI 1.0-6.1); p=0.12) patients but this was not statistically significant (see tables 5, 6). This observation does not suggest that the association of TNF2 with PSC is independent of these alleles but may be the result of the small numbers of patients and controls positive for TNF2 but negative for the other alleles.

Although there was a strong association between PSC and IBD ( $85 \%$ of PSC patients 
included in this study had underlying IBD), the significant difference in the distribution of the TNF -308 genotypes in PSC patients versus controls was found in both PSC patients with and without underlying IBD (see table 2). As over representation of the TNF2 allele is independent of the presence or absence of IBD, this clearly suggests that the association of the TNF2 allele with susceptibility to PSC is not secondary to the powerful association between PSC and IBD. Moreover, a number of previous studies ${ }^{23} 33{ }^{34}$ have failed to show any association between possession of TNF polymorphisms and susceptibility to ulcerative colitis.

IL-10 has several important roles in the modulation of the immune response, particularly in the peripheral maintenance of self tolerance. IL-10 produced by regulatory CD4+ $\mathrm{T}$ cells or $\mathrm{Th} 2$ cells cross regulates induction of proinflammatory or Th1 type CD4+ $T$ helper cell responses. Th1 type responses involved in cell mediated immunity have been implicated in the development of autoimmunity in both experimental models and human disease and IL-10 has been shown to have a protective effect against the development of disease in animal models of autoimmunity. ${ }^{35}$ Recently, we reported ${ }^{20}$ decreased expression of IL-10 mRNA in the livers of patients with PSC suggesting that decreased secretion of this cytokine and absence of its inhibitory effect on Th1 responses may be implicated in the pathogenesis of PSC. In the current study we examined the relationship between a potentially functional polymorphism at position -627 in the IL-10 promoter gene on chromosome 1 and susceptibility to PSC. Despite the probable role played by IL-10 in preventing the breakdown of self tolerance and evidence of decreased IL-10 transcription in PSC livers, we found no association between the IL-10 -627 promoter polymorphism and PSC.

IL-10 also has a role in fibrogenesis and modulates matrix and metalloprotease gene expression in fibroblasts. ${ }^{37}$ IL-10 expressed by activated hepatic stellate cells ${ }^{38}$ downregulates collagen gene and upregulates MMP-1 (collagenase I) gene expression. Possession of a $\mathrm{C} \rightarrow \mathrm{A}$ substitution at -627 in the IL-10 promoter is associated with increased fibrosis in animal models of liver injury ${ }^{39}$ and an increased risk of fibrotic alcoholic liver disease. ${ }^{40}$ Although PSC is a fibro-obliterative disease characterised by peribiliary fibrosis and eventually biliary cirrhosis, ${ }^{41}$ we did not find any relationship in this study between the IL-10 -627 polymorphism and disease severity or progression.

A number of possibilities may explain the findings in this study. The TNF2 allele may be directly implicated in determining susceptibility to PSC. As the strength of the association between TNF2 and PSC appeared to differ in these two northern European populations of PSC patients, the more likely explanation is that the association of the TNF2 allele with susceptibility to PSC is secondary to a "true" susceptibility gene or genes. Studies of other HLA class III genes or other genes in linkage with the extended haplotype A1-B8DRB1*0301-DQA $1{ }^{\star} 0501-\mathrm{DQB} 1{ }^{\star} 0201-\mathrm{TNF} 2$ may identify potential genes which may have a "primary" pathogenetic role in PSC.

This study was supported by the European Union, contract BMH4-CT96-0779.

\section{Appendix}

The European Study Group of Primary Sclerosing Cholangitis consists of the following participants:

Liver Unit, Hospital Clinic I Provincial, University of Barcelona, Villaroel 170, E-08036 Barcelona, Spain: A Pares, J Rodés, L Caballerie; Unit of Gastroenterology and Hepatology, Huddinge University Hospital, S-141 86 Huddinge, Sweden: A Bergquist, H Glaumann, R Hultcrantz, O Olerup, R Olsson, S Saarinen, A Scheynius, U Broome; Medical Department A, National Hospital, 0027 Oslo, Norway: K M Boberg, O P Clausen, T Egeland, O Fausa, T Halstensen, I Knutsen, K E A Lundin, A Spurkland, A Schjolberg, E Schrumpf; Gastroenterology Unit, fohn Radcliffe, Headington, Oxford OX 9DU, UK: K Fleming, S Mitchell, R Chapman; Dip. Speriment di Gastroenterology, Ospedale Molinette, $C$ so Bramente 88, 10126 Torino, Italy: M Bauducci, B Marchisio, S Recchia, G Rocca, R Volpes, F Rosina.

1 Chapman RW, Arborgh BA, Rhodes JM, et al. Primary sclerosing cholangitis: a review of its clinical features, cholangiography, and hepatic histology. Gut 1980;21:870-7.

2 Farrant JM, Doherty DG, Donaldson PT, et al. Amino acid substitutions at position 38 of the DR beta polypeptide confer susceptibility to and protection from primary sclerosing cholangitis. Hepatology 1992;16:390-5.

3 Mehal WZ, Lo YM, Wordsworth BP, et al. HLA DR4 is a marker for rapid disease progression in primary sclerosing cholangitis. Gastroenterology 1994;106:160-7.

4 Olerup O, Olsson R, Hultcrantz R, et al. HLA-DR and HLA-DQ are not markers for rapid disease progression in primary sclerosing cholangitis. Gastroenterology 1995;108: primary

5 Spurkland A, Saarinen S, Boberg KM, et al. HLA class II haplotypes in primary sclerosing cholangitis patients from five European populations. Tissue Antigens 1999;53:45969.

6 Wilson AG, Gordon C, di Giovine FS, et al. A genetic association between systemic lupus erythematosus and tumor necrosis factor alpha. Eur f Immunol 1994;24:191-5.

7 Danis VA, Millington M, Hyland V, et al. Increased frequency of the uncommon allele of a tumour necrosis factor alpha gene polymorphism in rheumatoid arthritis and systemic lupus erythematosus. Dis Markers 1995;12: 127-33.

8 Wilson AG, di Giovine FS, Duff GW. Genetics of tumour necrosis factor-alpha in autoimmune, infectious, and neoplastic diseases. F Inflamm 1995;45:1-12.

9 Manus RM, Wilson AG, Mansfield J, et al. TNF2, a polymorphism of the tumour necrosis-alpha gene promoter, is a component of the celiac disease major histocompatibility complex haplotype. Eur $\mathcal{f}$ Immunol 1996;26:2113-18.

10 Kroeger KM, Carville KS, Abraham LJ. The -308 tumor necrosis factor-alpha promoter polymorphism effects transcription. Mol Immunol 1997;34:391-9.

11 Braun N, Michel U, Ernst BP, et al. Gene polymorphism at position -308 of the tumor-necrosis-factor-alpha (TNFalpha) in multiple sclerosis and its influence on the regulation of TNF-alpha production. Neurosci Lett 1996;215:75-

12 Wilson AG, Symons JA, McDowell TL, et al. Effects of a polymorphism in the human tumor necrosis factor alpha promoter on transcriptional activation. Proc Natl Acad Sci USA 1997;94:3195-9.

13 Brinkman BM, Zuijdeest D, Kaijzel EL, et al. Relevance of the tumor necrosis factor alpha (TNF alpha) - 308 promoter polymorphism in TNF alpha gene regulation. $\mathcal{f}$ promoter polymorphism

14 Wilson AG, de Vries N, Pociot F, et al. An allelic polymorphism within the human tumor necrosis factor alpha promoter region is strongly associated with HLA A1, B8, and DR3 alleles. F Exp Med 1993;177:557-60.

15 Liblau RS, Singer SM, McDevitt HO. Th1 and Th2 CD4+ $T$ cells in the pathogenesis of organ-specific autoimmune diseases. Immunol Today 1995;16:34-8.

16 Hobbs K, Negri J, Klinnert M, et al. Interleukin-10 and transforming growth factor-beta promoter polymorphisms in allergies and asthma. Am $\mathcal{f}$ Respir Crit Care Med 1998;158:1958-62.

17 Borish L, Aarons A, Rumbyrt J, et al. Interleukin-10 regulation in normal subjects and patients with asthma. F Allergy Clin Immunol 1996;97:1288-96.

18 Park YB, Lee SK, Kim DS, et al. Elevated interleukin-10 levels correlated with disease activity in systemic lupus erythematosus. Clin Exp Rheumatol 1998;16:283-8. 
19 Lazarus M, Hajeer AH, Turner D, et al. Genetic variation in the interleukin 10 gene promoter and systemic lupus

20 Mitchell SA, Fleming K, Chapman RW. Decreased interleukin-10 mRNA expression in primary sclerosing cholangitis and primary biliary cirrhosis: a role for IL-10 in the pathogenesis? Hepatology 1997;26(4):442A.

21 Turner DM, Williams DM, Sankaran D, et al. An investigation of polymorphism in the interleukin-10 gene promoter. Eur f Immunogenet 1997;24:1-8.

22 Verjans GM, Brinkman BM, Van Doornik CE, et al. Polymorphism of tumour necrosis factor-alpha (TNFalpha) at position -308 in relation to ankylosing spondylitis. Clin Exp Immunol 1994;97:45-7.

23 Louis E, Satsangi J, Roussomoustakaki M, et al. Cytokine gene polymorphisms in inflammatory bowel disease. Gut 1996;39:705-10.

24 Zappala F, Grove J, Watt FE, et al. No evidence for involvement of the interleukin-10 -592 promoter polymorphism in genetic susceptibility to primary biliary cirrhosis. in genetic susceptibility

25 Tiwaris JL, Teraski PI. HLA and disease associations. New York: Springer-Verlag, 1985:18-27.

26 Svejgaard A, Ryder LP. HLA and disease associations: Svejgaard A, Ryder LP. HLA and disease associations:
Detecting the strongest association. Tissue Antigens 1994; 43:18-27.

27 Donaldson PT. Immunogenetics and epidemiology of primary sclerosing cholangitis. In: Manns MP, Chapman $\mathrm{RW}$, Stiehl A, et al, eds. Primary sclerosing cholangitis. Dordrecht: Kluwer Academic Publishers, 1998:22-36.

28 Turner DM, Grant SC, Lamb WR, et al. A genetic marker of high TNF-alpha production in heart transplant recipients. Transplantation 1995;60:1113-17.

29 McGuire W, Hill AV, Allsopp CE, et al. Variation in the TNF-alpha promoter region associated with susceptibility to cerebral malaria. Nature 1994;371:508-10.

30 Gordon MA, Oppenheim E, Camp NJ, et al. Primary biliary cirrhosis shows association with genetic polymorphism of cirrhosis shows association with genetic polymorphism of
tumour necrosis factor alpha promoter region. $\mathscr{J}$ Hepatol 1999;31:242-7.
31 Jones DEJ, Watt FE, Grove J, et al. Tumour necrosis factoralpha promoter polymorphisms in primary biliary cirrhosis. 7 Hepatol 1999;30:232-6.

32 Bernal W, Moloney M, Underhill J, et al. Association of tumor necrosis factor polymorphism with primary sclerosing cholangitis . F Hepatol 1999;30:237-41.

33 Bouma G, Crusius JB, Garcia-Gonzalez MA, et al. Genetic markers in clinically well defined patients with ulcerative colitis (UC). Clin Exp Immunol 1999;115:294-300.

34 Heresbach D, Ababou A, Bourienne A, et al. Polymorphism of the microsatellites and tumor necrosis factor genes in chronic inflammatory bowel diseases. Gastroenterol Clin Biol 1997;21:555-61.

35 Liblau RS, Singer SM, McDevitt HO. Th1 and Th2 CD4+ $T$ cells in the pathogenesis of organ-specific autoimmune diseases. Immunol Today 1995;16:34-8.

36 Fowell D, Mason D. Evidence that the T cell repertoire of normal rats contains cells with the potential to cause diabetes. Characterization of the CD4+ T cell subset that inhibits this autoimmune potential. F Exp Med 1993;177: 627-36.

37 Thompson K, Maltby J, Fallowfield J, et al. Interleukin-10 expression and function in experimental murine liver inflammation and fibrosis. Hepatology 1998;28:1597-606.

38 Wang SC, Ohata M, Schrum L, et al. Expression of interleukin-10 by in vitro and in vivo activated hepatic stellate cells. F Biol Chem 1998;273:302-8.

39 Louis H, Van Laethem JL, Wu W, et al. Interleukin-10 controls neutrophilic infiltration, hepatocyte proliferation, and liver fibrosis induced by carbon tetrachloride in mice. Hepatology 1998;28:1607-15.

40 Grove J, Daly AK, Bassendine MF, et al. Interleukin 10 promoter region polymorphisms and susceptibility to advanced alcoholic liver disease. Gut 2000;46:540-5.

41 Ludwig J. Histopathology of primary sclerosing cholangitis. In: Manns MP, Chapman RW, Stiehl A, et al, editors. Primary sclerosing cholangitis. Dordrecht: Kluwer Academic Publishers, 1998:14-21. 